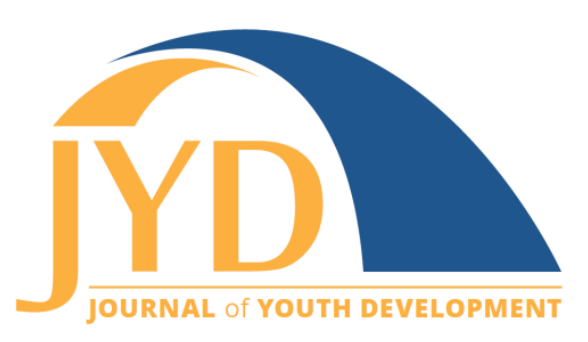

http://jyd.pitt.edu/ | Vol. 15 Issue 1 DOI 10.5195/jyd.2020.822 | ISSN 2325-4017 (online)

\title{
Motivations and Barriers for Seasonal Camp Employment
}

\author{
Dan Richmond \\ University of Utah \\ dan.richmond@utah.edu \\ Jim Sibthorp \\ University of Utah \\ jim.sibthorp@health.utah.edu
}

\section{Deborah Bialeschki}

American Camp Association

dbialeschki@acacamps.org

\begin{abstract}
Each year, many summer camps deal with the challenges related to retaining quality seasonal staff. Retaining seasonal staff from year to year requires knowing what motivates staff to return and understanding the factors that drive voluntary turnover. While research on employee retention and turnover is abundant in management literature, few studies have focused on seasonal summer camp staff. This study used a mixed-methods design and involved a national sample of 997 returning camp staff from a variety of camp types. Respondents completed an online survey that included a 40-item questionnaire measuring staff motivations to return to camp and a series of open-ended questions on drivers of retention and turnover. Exploratory factor analysis and confirmatory factor analysis revealed 7 latent constructs that drive motivation. Within the whole sample, Job Impact had the highest subscale mean score followed by Camp Embeddedness, Value Alignment, Staff Development, Management, Job Fit, and Compensation. Analysis of open-ended responses confirmed that Job Impact and Camp Embeddedness were the primary motivations for seasonal camp staff to return and that Compensation, Poor Job Fit, and Other Opportunities were likely drivers of turnover. This study helps paint a picture of the key factors that bring back seasonal staff and the factors, both controllable and uncontrollable, that lead camp staff to pursue other opportunities. Findings may be especially useful to professionals in the camping industry interested in seeking out potential camp staff and retaining staff year over year.
\end{abstract}

Key words: summer camp, staff retention, employee motivation, staff development

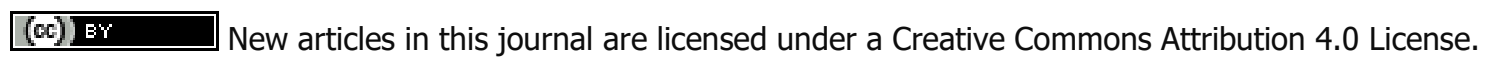
This journal is published by the University Library System, University of Pittsburgh and is cosponsored by the University of Pittsburgh Press. The Journal of Youth Development is the official peer-reviewed publication of the National Association of Extension 4-H Youth Development Professionals and the National AfterSchool Association. 
Retaining quality employees remains a challenge for many seasonal industries, including summer camps (Kusluvan, Kusluvan, Ilhan, \& Buyruk, 2010). Indeed, many summer camps need to replace more than $40 \%$ of their seasonal staff each year (American Camp Association, 2016). Staff turnover affects both financial and organizational performance-organizations must spend additional funds to recruit, select and train new staff while also compensating for the loss of valuable institutional knowledge and its impact on customer service and organizational efficiency (Hancock, Allen, Bosco, McDaniel, \& Pierce, 2013). While some turnover is necessary or even healthy, summer camps need to understand what motivates employees to return if they want to recruit and retain the desired staff.

The purpose of this study was to build on existing research on seasonal summer camp employment (e.g., DeGraff \& Glover, 2003; Duerden et al., 2014; Henderson, Bialeschki, \& James, 2007; McCole, Jacobs, Lindley, \& McAvoy, 2012) to understand the employment motivations of returning camp staff from a nationally representative sample. A secondary purpose of the study was to explore motivations that may drive camp staff turnover.

\section{Background}

Research in human resource management has examined the issues of staff retention and turnover for decades. Retaining high-quality staff helps ensure that organizations meet their performance goals and maintain a healthy organizational culture (Hancock et al., 2013; Mitchell, Holtom, \& Lee, 2001; Selden \& Sowa, 2015). Replacing staff can be costly with estimates for replacing an experienced employee at $90 \%$ to $200 \%$ of annual salary in certain industries (Hom, Lee, Shaw, \& Hausknecht, 2017). The costs of replacement include the direct costs of recruiting, selecting, and training employees as well as indirect costs associated with lost productivity, the loss of institutional knowledge, and the time required by new employees to establish relationships that support success (Hom et al., 2017; Kusluvan et al., 2010; Selden \& Sowa, 2015).

Two basic types of employee turnover exist: involuntary turnover (i.e., firings and layoffs) and voluntary turnover (i.e., the employee chooses to separate from their job and leave the organization; Allen \& Vardaman, 2017; Hom et al., 2017). While seasonal employers like summer camps do have to let go employees for poor performance and other reasons like a discordant person-organization fit, the primary path for losing employees from season to season is due to voluntary turnover (American Camp Association, 2016). As every industry is 
slightly different, a need exists to understand what motivates individuals to return to camp employment while also considering the drivers of turnover, as camps must regularly replace staff on a year-to-year basis (Henderson et al., 2007; McCole et al., 2012).

Factors in three main areas drive retention and turnover: external economic and job market conditions, the organization, and aspects internal to the employee (Lee, Hom, Eberly, \& Li, 2018; Selden \& Sowa, 2015). External conditions include the availability of other jobs and related economic factors related to switching jobs. Organizational and employee factors include (a) staff recruitment, selection, and staffing; (b) compensation and nonmonetary rewards; (c) training and development; (d) management and supervision; (e) feedback on performance; (f) job engagement; and ( $\mathrm{g}$ ) job embeddedness (Allen, Bryant, \& Vardaman, 2010; Kusluvan et al., 2010; Selden \& Sowa, 2015). Alternative paths to voluntary turnover other than job dissatisfaction include more attractive alternatives, life scripts or plans (e.g., graduation, marriage, kids), and what HR literature refers to as "impulsive quits" by employees (Allen et al., 2010).

\section{Staff Recruitment and Selection}

Staff recruitment and selection are highly predictive factors related to employee retention (Lee et al., 2018; Mitchell et al., 2001; Selden \& Sowa, 2015). The staffing process includes the selection of qualified individuals who are a good fit for the job position in terms of skills and overall socialization within the organization (Posthuma \& Campion, 2013). In other words, employees who are likely to stay are those that have the right mix of job-related competencies along with the behavioral dispositions that match the needs of the position. Research on camp employees found that many former camp employees noted that they were motivated to work at camp due to previous experience as camp participants, an interest in the job responsibilities like working with kids, and an affinity for the working environment (DeGraff \& Glover, 2003; Duerden et al., 2014).

\section{Compensation and Non-Monetary Rewards}

Compensation and non-monetary rewards include pay and other benefits related to the position. The literature on human resource management has consistently noted that perceptions of pay fairness as well as perceptions of pay being connected to performance can drive turnover and retention (Allen et al., 2010; Selden \& Sowa, 2015). However, Allen and colleagues (2010) observed that pay is a weaker predictor of retention and turnover than many 
expect. Indeed, in a study of former camp employees, Duerden and colleagues (2014) interviewed former camp staff and many interviewees noted that they worked at camp for reasons other than the paycheck.

\section{Staff Training and Development}

Staff training and opportunities for development are particular factors that have been shown to be more predictive of retention and turnover than compensation (Selden \& Sowa, 2015). Quality staff training and opportunities for advancement are linked to higher levels of employee satisfaction (Lee et al., 2018; Posthuma \& Campion, 2013). When employers invest in training, staff may feel that they are valued. When training leads to advancement, employees may be more motivated to stay in an organization as long as available job opportunities align with personal goals (Allen et al., 2010). While limited retention and turnover research exists on seasonal summer camp employees, existing studies have found former camp employees valued their training and experience, specifically their leadership development and skills related to future employment (DeGraff \& Glover, 2003; Duerden et al., 2014).

\section{Management and Supervision}

Management plays a key role in the training and development of staff and contributes to overall employee satisfaction. When employers have good relationships with their employees, share information, and listen to employee input, employee performance and retention improve (Allen et al., 2010; Brown, Gray, McHardy, \& Taylor, 2015; Govaerts, Kyndt, Dochy, \& Baert, 2011). Conversely, perceptions of poor management have been identified as a driver of turnover in nearly every industry including camp (see Duerden et al., 2014).

\section{Feedback on Performance}

Feedback is something organizations can offer to employees to improve perceptions of management and employee retention. Research, including studies involving camp staff, has found that employee retention is related to receiving positive and growth-oriented feedback from supervisors (Allen et al., 2010; Duerden et al., 2014; Kusluvan et al., 2010). Positive feedback from co-workers and clients can also contribute to overall job satisfaction (Hausknecht, Rodda, \& Howard, 2009; Selden \& Sowa, 2015). 


\section{Engagement}

Job satisfaction and retention are often driven by perceptions of job engagement, where employees find the work meaningful and interesting and have some sense of autonomy (Allen et al., 2010; Selden \& Sowa, 2015). Duerden et al. (2014) found that engagement was a key motivator for returning camp staff with an emphasis on the feeling that staff members were making a difference with campers.

\section{Job Embeddedness}

Job engagement is closely related to another factor that can influence retention: job embeddedness. Job embeddedness involves "links" or relationships within the organization, job and organizational fit, and the perceived personal sacrifices of leaving a job (Allen et al., 2010; Lee et al., 2018). According to Allen et al. (2010, p. 56):

Links are connections with other people, groups, or organizations, such as coworkers, work groups, mentors, friends, and relatives. Fit represents the extent to which an employee sees himself as compatible with his job, organization, and community. . . . Sacrifice represents what would be given up by leaving a job and could include financial rewards based on tenure, a positive work environment, promotional opportunities, and community. Employees with numerous links to others in their organization and community who fit better with their organization and community, and who would have to sacrifice more by leaving are more embedded and likely to stay.

Seasonal camp employees who are motivated to return likely have strong relationships within the camp community, identify with the mission and culture of camp, and feel like they would be missing out on the positive aspects of camp if they did not return. Existing research on camp staff has noted the importance of the camp community, friendships, relationships with campers, and the fun work environment to returning staff (Duerden et al., 2014; McCole et al., 2012).

\section{Other Factors Driving Turnover}

While the factors related to job satisfaction discussed thus far are highly related to turnover and retention, additional factors that contribute to turnover are not necessarily related to satisfaction. These factors include life scripts (e.g., graduating from college, marriage, having children), better job alternatives, and impulsive quits (Allen et al., 2010). These factors also 


\section{Motivations and Barriers for Seasonal Camp Employment}

influence turnover in seasonal employment at summer camps (cf. McCole, 2012). Many camp staff leave because they graduate from college and move on to year-round employment in their field or their family situation changes. Other staff may not return to camp in order to pursue opportunities like travel or study abroad. Often, these factors are beyond the control of employers (Hom et al., 2017).

\section{Research Need and Study Purpose}

While a vast amount of research on turnover and retention exists, very little research has focused on seasonal summer camp staff. Much of the research on camp staff has focused on outcomes of staff employment (Duerden et al., 2014; Henderson et al., 2007; Powell, Bixler, \& Switzer, 2003). While some research can be found related to retention and turnover with seasonal summer camp staff, many studies focused on a single camp (e.g., DeGraff \& Glover, 2003; Duerden et al., 2014; Wahl-Alexander, Richards, \& Washburn, 2017). Other studies on camp employee retention focused on a limited set of motivating factors like a sense of community (e.g., McCole et al., 2012). A need remains to identify what motivates camp staff to return and what factors may drive them to leave. Findings would help camp leaders understand where to focus their attention in order to keep their best employees while also gaining insight on aspects of turnover that are less within their control. Therefore, the purpose of this study was to identify the primary drivers of retention and turnover from a nationally representative sample of returning summer camp staff.

\section{Methods}

We collected survey data from 997 respondents identified as returning camp staff before the summer of 2018. Participants were recruited from 44 geographically diverse camps in the United States with assistance from the American Camp Association (ACA) with the goal of representing the ACA's breadth of camps and participant groups. The sample included overnight camps, day camps, nonprofit and for-profit camps, and single-gender and co-ed camps (see Table 1). 
Table 1. Summary of Camps Represented in Study $(n=44)$

\begin{tabular}{|l|c|}
\hline Programs offered & $n$ \\
\hline Overnight camp only & 24 \\
\hline Day camp only & 10 \\
\hline Both overnight and day camps offered & 10 \\
\hline Region & \\
\hline New England & 11 \\
\hline NY/NJ & 6 \\
\hline Atlantic Coast & 5 \\
\hline Midwest & 12 \\
\hline West Coast & 6 \\
\hline Rocky Mountain and Southwest & 2 \\
\hline Pacific Northwest & 2 \\
\hline Type & \\
\hline Independent for profit & 13 \\
\hline Independent nonprofit & 10 \\
\hline Agency-affiliated & 14 \\
\hline Religious-affiliated & 7 \\
\hline & \\
\hline Single-gender & 6 \\
\hline
\end{tabular}

Note. Agency-affiliated camps are nonprofit camps affiliated with larger nonprofit organizations (e.g., YMCA, Girl Scouts, Boys and Girls Club, Campfire, etc.). Religious-affiliated camps are those associated with nonprofit religious organizations.

Camps sent out emails to all staff hired for summer 2018 inviting them to participate in the study. The email included a link to opt in to the study and complete an online survey. Among those that opted in, responses were screened to include only staff hired for the upcoming summer who had worked at camp at least one previous season.

\section{Instrument}

Respondents completed an online survey that included a 40-item questionnaire measuring staff motivations to return to camp. Questions on motivation for returning were based on drivers 
identified in the literature (sample item: "I returned to a job at camp because ... I am paid well."). Responses ranged from 1 (Very False) to 10 (Very True).

Respondents also completed a series of open-ended questions related to retention and turnover. One question was used to gain insight on motivations to return by asking respondents the main reason they returned to camp. An open-ended question was also included that asked about turnover: "What do you think are the top three reasons camp staff don't return to summer camp employment?" Finally, a question asked respondents about the opportunity costs of working at camp: "What are three things that you won't be able to do because you are working at camp this summer that might also be important to you?"

\section{Data Analysis}

After data screening and cleaning, the researchers evaluated the scaled items using exploratory factor analysis (EFA) and confirmatory factor analysis (CFA) to understand the latent structure of responses and determine how well the resulting factors mapped onto existing literature and theory. Initially, EFA was used on a randomly selected half of the sample; a confirmatory factor analysis (CFA) was then used to verify the robustness of the proposed factor structure on the remaining half of the data. This approach is known as cross-validation and allows for anticipated constructs to be refined through EFA and then confirmed through CFA. Using the full sample $(N=997)$, mean scores were then calculated for each confirmed subscale. Openended questions were analyzed using open and focused coding processes to narrow down response themes (Miles, Huberman, \& Saldana, 2014).

\section{Results}

Approximately $64 \%$ of the respondents identified as female and $1 \%$ identified as gender nonconforming. Respondents identified as White (85.2\%), Hispanic or Latino/a (5.6\%), Black or African American (3.5\%), Multi-Racial (3.0\%), Asian (1.4\%) and other (1.1\%). The average age was 22.8 years. Over $50 \%$ had two or fewer years of camp job experience prior to returning to camp employment, $83.9 \%$ attended camp as a camper and $61.3 \%$ participated in counselor-intraining (CIT), leader-in-training (LIT), or similar programs before they worked as seasonal camp staff. 


\section{EFA and CFA}

The EFA resulted in seven retained factors for the original 40 item motivations scale. The factors were largely consistent with the literature on seasonal employment and represented constructs labeled Job Impact, Camp Embeddedness, Value Alignment, Staff Development, Management, Job Fit, and Compensation. As we had initially written items to capture 10 potential domains rather that the seven we retained, seven items were removed from the item pool. Two anticipated domains centered on interest in the work and opportunity to use past experience were empirically indistinct and were collapsed into Job Fit in our model. Likewise, two domains centered on social relationships and emotional attachment were collapsed into Camp Embeddedness; and two domains focused on learning new things and career preparation were collapsed into Staff Development. This re-conceptualized factor structure allowed us to remove seven items either considered redundant with the retained items or that cross-loaded across two or more factors prior to validating the structure using CFA. The retained motivations item pool included 33 items thought to best represent the content coverage of the seven factors, with 4-6 items per subscale.

CFA was then conducted on the second half of the sample to assess the robustness of the proposed factor structure. The model fit was adequate, $\chi^{2}=1416, d f=467, p<.01$; root mean square error of approximation (RMSEA) = .066; goodness of fit index $(\mathrm{GFI})=.846$; comparative fit index $(\mathrm{CFI})=.923$; normed fit index $(\mathrm{NFI})=.889$. The moderate to high correlations between some of the factors presented opportunities to improve model fit by collapsing factors together. However, the authors decided to rely on theoretically proposed distinctions despite empirical evidence that these distinctions were not always clear to the study participants. Table 2 shows the survey items that fit within each motivation subscale.

\section{Table 2. Motivation Subscales and Items}

\begin{tabular}{|l|l|}
\hline Subscale & Items \\
\hline Job impact & I have the opportunity to serve as a role model. \\
\hline The campers say they like me. \\
\hline & I received positive feedback from the parents of campers. \\
\hline Other staff say I am good at this job. \\
\hline I can make a difference. \\
\hline & I have the opportunity to mentor others. \\
\hline
\end{tabular}


Table 2. (continued)

\begin{tabular}{|c|c|}
\hline Subscale & Items \\
\hline \multirow[t]{5}{*}{ Camp embeddedness } & I have positive memories from this camp. \\
\hline & I have an emotional attachment to this camp. \\
\hline & I can reconnect with friends. \\
\hline & I can make new friends. \\
\hline & I like the natural environment. ${ }^{a}$ \\
\hline \multirow[t]{4}{*}{ Value alignment } & I identify with the overall mission of the camp. \\
\hline & The camp shares my worldview. \\
\hline & The camp aligns with my personal values. \\
\hline & I am passionate about the programming. \\
\hline \multirow[t]{4}{*}{ Staff development } & I am able to learn new things. \\
\hline & I can take on more responsibility this summer. \\
\hline & I can gain experience that prepares me for a job or career. \\
\hline & I have opportunities to grow and develop personally. \\
\hline \multirow[t]{4}{*}{ Management } & I get along well with my supervisors. \\
\hline & My supervisors listen and consider my feedback. \\
\hline & Supervisors communicate well with staff. \\
\hline & I believe the camp is managed well. \\
\hline \multirow[t]{6}{*}{ Job fit } & It is a good match for my skills and abilities. \\
\hline & I find the work interesting. \\
\hline & It allows me to use my education. \\
\hline & It aligns with my previous work experience. \\
\hline & There is variety in the work. \\
\hline & I can make some important decisions on my own. \\
\hline \multirow[t]{4}{*}{ Compensation } & I am paid well. \\
\hline & The pay is fair. \\
\hline & I am rewarded for excellent performance. \\
\hline & I like other benefits like lodging and food. \\
\hline
\end{tabular}

Note. Each of the items had the same question stem ("I am returning to camp because . . .). Responses ranged from 1 (Very False) to 10 (Very True).

a This item might be revised to "I like the environment" in future use, as some camps operate in highly developed settings. 


\section{Drivers of Retention Subscale Means}

Job Impact had the highest mean score among all subscales, $M=9.181$. Job impact was followed by Camp Embeddedness, Value Alignment, Staff Development, Management, and Job Fit. Compensation had the lowest mean score. Each subscale had good internal consistency (a $=.839$ to $\mathrm{a}=.932)$. See Table 3 .

Table 3. Motivation Subscale Reliabilities and Means

\begin{tabular}{|l|c|c|c|c|c|}
\hline & & & & \multicolumn{2}{|c|}{$\begin{array}{c}95 \% \text { Confidence } \\
\text { Interval }\end{array}$} \\
\hline Subscale & Items & $\mathbf{a}$ & Mean & Lower & Upper \\
\hline Job impact & 6 & .893 & 9.181 & 9.120 & 9.262 \\
\hline Camp embeddedness & 5 & .840 & 9.050 & 8.952 & 9.122 \\
\hline Value alignment & 4 & .899 & 8.923 & 8.835 & 9.012 \\
\hline Staff development & 4 & .848 & 8.831 & 8.744 & 8.930 \\
\hline Management & 4 & .932 & 8.754 & 8.676 & 8.883 \\
\hline Job fit & 6 & .839 & 8.696 & 8.624 & 8.795 \\
\hline Compensation & 4 & .852 & 7.163 & 7.030 & 7.308 \\
\hline
\end{tabular}

Note. $N=927$. Missing data were removed listwise. Confidence intervals displayed are the upper and lower bounds of the mean at a $95 \%$ confidence interval for the sample $n$. If the mean of one subscale is not within the confidence interval of another subscale, the subscale differences are significant.

Correlations between subscales ranged from weak $(r=.330)$ to moderate $(r=.697)$. These correlations demonstrate that each of the subscales is positively associated with a desire to return to camp employment, but the strength of these correlations varies. For example, Job Impact has a low correlation with Compensation, demonstrating that the relationship between these two drivers of retention is weak. See Table 4. 
Motivations and Barriers for Seasonal Camp Employment

Table 4. Subscale Mean Correlations

\begin{tabular}{|l|c|c|c|c|c|c|c|}
\hline Subscale & 1 & 2 & 3 & 4 & 5 & 6 & 7 \\
\hline Job impact & 1.000 & & & & & & \\
\hline Camp embeddedness & .536 & 1.000 & & & & & \\
\hline Value alignment & .660 & .566 & 1.000 & & & & \\
\hline Staff development & .617 & .499 & .583 & 1.000 & & & \\
\hline Management & .472 & .352 & .504 & .498 & 1.000 & & \\
\hline Job fit & .697 & .511 & .653 & .670 & .512 & 1.000 & \\
\hline Compensation & .388 & .330 & .436 & .449 & .604 & .468 & 1.000 \\
\hline
\end{tabular}

Note. Pearson correlations $(N=927)$. All correlations are significant $(p<.01)$. Missing data were removed listwise.

\section{Motivations for Retention from Qualitative Data}

\section{Job Impact as a Primary Driver of Retention}

Returning staff had the opportunity to expand on their motivations for returning to camp through open-ended questions in the survey. There were 957 responses to the open-ended question asking respondents for the main reason they came back to camp. The coding process found that approximately $34 \%$ of the open-ended responses included reasons related to Job Impact as the primary driver of returning to camp. Respondents noted their return to camp was driven by an interest in making a difference on the campers, giving other youth the types of positive experiences like they had as campers, and seeing growth in the campers during the session or from year to year. They also often noted that they returned to camp work because they found it personally rewarding. Table 5 displays response subthemes and representative quotes related to Job Impact. 
Motivations and Barriers for Seasonal Camp Employment

Table 5. Job Impact Representative Quotes

\begin{tabular}{|l|l|}
\hline Subtheme & Representative quotes \\
\hline Impact on kids & $\begin{array}{l}\text { "The main reason I came back was because I am passionate about making a } \\
\text { difference to the people that surround me. I want to use my gifts and skills to } \\
\text { make sure that hundreds of kids every summer have the best week of their year } \\
\text { at camp." }\end{array}$ \\
\hline $\begin{array}{l}\text { Giving others a } \\
\text { quality } \\
\text { experience }\end{array}$ & $\begin{array}{l}\text { "The impact I have seen that summer camp has on anyone that comes to camp." } \\
\text { confidence to be myself. Other girls deserve a safe place to do that too." }\end{array}$ \\
\hline $\begin{array}{l}\text { Helping campers } \\
\text { grow }\end{array}$ & $\begin{array}{l}\text { "The main reason that I returned to camp is because it has become a passion of } \\
\text { mine to work with kids and to help them grow. . . The campers that I have met } \\
\text { and are returning also push me to return so I can see them again." }\end{array}$ \\
\hline Rewarding work & $\begin{array}{l}\text { "I truly find nothing more fulfilling than working with children. Being a camp } \\
\text { counselor can be demanding and challenging, but it doesn't even feel like a job } \\
\text { because I love it so much! There is nothing I'd rather spend my summer doing." }\end{array}$ \\
\hline
\end{tabular}

\section{Camp Embeddedness as a Primary Driver of Retention}

Approximately $32 \%$ of the responses mentioned reasons related to Camp Embeddedness as the primary drivers of retention. Responses identified friendships and other relationships, the camp environment, and a desire to build on previous positive experiences at camp as reasons to return. Many of these respondents also referred to camp as a "second home" in ways that referenced their comfort within the camp environment and that they would miss it if they did not return. Table 6 summarizes Camp Embeddedness subthemes and representative responses. 
Motivations and Barriers for Seasonal Camp Employment

Table 6. Camp Embeddedness Representative Quotes

\begin{tabular}{|l|l|}
\hline Subtheme & Representative quotes \\
\hline Relationships & $\begin{array}{l}\text { "The main reason that I returned to work at camp this summer is that I love } \\
\text { the relationships that I have with everyone there including the staff, CITS, and } \\
\text { campers." }\end{array}$ \\
\hline $\begin{array}{l}\text { Camp } \\
\text { environment }\end{array}$ & $\begin{array}{l}\text { "Because I believe in the spirit that is embodied by the people there, both } \\
\text { campers and staff, and the good that that environment can do for so many } \\
\text { people." }\end{array}$ \\
& $\begin{array}{l}\text { "I love the community, the people, and getting to work with kids in the } \\
\text { outdoors." }\end{array}$ \\
& "I enjoy working with my co-workers in an outdoor setting." \\
& $\begin{array}{l}\text { "I appreciate a chance to spend a summer in a natural environment away from } \\
\text { the stresses of city life." }\end{array}$ \\
\hline $\begin{array}{l}\text { Continue positive } \\
\text { experiences }\end{array}$ & $\begin{array}{l}\text { "I wanted to return again because of my experiences last summer and this } \\
\text { would be my last chance to return." }\end{array}$ \\
\hline $\begin{array}{l}\text { Camp as a } \\
\text { second home }\end{array}$ & $\begin{array}{l}\text { "It's my second home. It's my escape from "the real world." I have never } \\
\text { missed a summer (don't plan to either)." }\end{array}$ \\
\hline
\end{tabular}

\section{Other Drivers of Retention}

While responses that represented the role of Job Impact and Camp Embeddedness as key drivers of retention made up roughly $66 \%$ of all responses-roughly aligning with the quantitative data-other responses did emerge that represented the other subscales of retention from the closed response portion of the survey. However, each of the remaining five subscales-Value Alignment, Staff Development, Management, Job Fit, and Pay-was represented by less than $7 \%$ of total responses. Some respondents reported that they returned to camp employment because the camp they worked for shared their worldview, offered opportunities to take on new responsibilities, had excellent management, and offered experiences that fit their interests and career goals. Just 13 respondents said that pay was the primary driver for returning to work at camp. 


\section{Barriers to Retention}

Analysis of the two additional open-ended questions revealed three main drivers of turnover and four areas where returning staff noted that they were missing out due to camp employment. Returning staff hypothesized that compensation, life scripts or other opportunities, and poor job fit were the main reasons individuals do not return to camp employment. Table 7 presents representative quotes for each theme related to retention barriers.

\section{Table 7. Barriers to Retention}

\begin{tabular}{|l|l|}
\hline $\begin{array}{l}\text { Drivers of } \\
\text { turnover }\end{array}$ & Representative quotes \\
\hline Compensation & "It does not pay enough to earn enough money for college, car payments, etc." \\
& "Pay - while it's hard to remember room and board is included, many feel as \\
though they can find a better-paying summer job."
\end{tabular}

Compensation was noted by over $40 \%$ of respondents as the primary driver of staff turnover, noting that camp pay is low and that many seek out higher-paying jobs. Life scripts and other opportunities were noted as the primary drivers of turnover by $35 \%$ of respondents. Life scripts included moving away for college; the need to participate in a career-related internships; graduating from college and moving on to a permanent, year-round job; aging out of camp work; and starting a family. Other opportunities included study abroad, better seasonal job opportunities, and the desire to "move on" from camp work. Poor job fit was reported as a primary driver of turnover by $15 \%$ of respondents. Poor job fit included employees not liking certain aspects of the job, particularly working with kids, the camp environment, or the long 
hours associated with the work. When asked about the opportunity costs associated with summer camp employment, the most common responses were that camp staff missed out on spending time with friends, other job opportunities, vacation, and education opportunities like summer school or study abroad.

\section{Discussion}

This study from a nationally representative sample of returning camp staff provides important insights on what motivates staff to return to a job at summer camp as well as factors that may drive turnover. Drivers related to retention and turnover roughly aligned with those identified in management literature (cf. Allen, Bryant, \& Vardaman, 2010; Selden \& Sowa, 2015) and those explored in previous studies on seasonal camp staff (Duerden et al., 2014; Henderson et al., 2007; McCole et al., 2012). However, this study expands the previous research by using a large national sample that included a wide variety of camp types from across the United States. This study helps paint a picture of the key factors that bring back seasonal staff and the factors, both controllable and uncontrollable, that lead camp staff to pursue other opportunities. Findings may be especially useful to professionals in the camping industry interested in seeking out potential camp staff and retaining staff year over year.

\section{Perceived Job Impact as a Primary Driver of Retention}

Findings from this study support that perceived Job Impact is a primary driver that motivates camp staff to return. Both quantitative and qualitative data demonstrated that within this sample, the perception of making a difference is influential in staff retention. Job Impact for camp staff includes the opportunity to serve as a role model; to mentor others; and then receive feedback from campers, the parents of campers, and peers that their efforts have made a difference. This finding is similar to other camp studies where making a difference with campers was a motivating factor to return (cf. DeGraff \& Glover, 2003; McCole et al., 2012). This study demonstrated that Job Impact may be the primary motivator for many returning staff.

Some literature in human resource management included Job Impact within a broader category of engagement where the work is interesting, meaningful, and individuals have a strong sense of autonomy (cf. Allen et al., 2010; Selden \& Sowa, 2015). In this study, the latent structure of responses paired meaningfulness, or perceived impact, with feedback on performance. As other 
Motivations and Barriers for Seasonal Camp Employment

literature has noted, positive feedback is a powerful motivator linked to retention (see Duerden et al., 2014; Hausknecht et al., 2009; Selden \& Sowa, 2015). Within the group of camp staff respondents, positive feedback served as powerful evidence of impact.

Meaningfulness of work and perceived impact were unsurprisingly powerful retention motivators for camp staff in this study. Meaningfulness has long been associated with motivation (see Maslow, 1970) and the importance of meaningful work regularly appeared in management literature (Fairlie, 2011; Kahn, 1990). Meaningful work and perceived impact have also been linked to increased motivation in education, where students were more likely to persevere through challenges if they believed that their future careers would serve a greater good or selftranscendent purpose (Nagaoka et al., 2015; Yeager et al., 2017, 2016). Within the summer camp environment, employees can see their impact on campers and receive almost immediate feedback on campers' responses to their influence. Though the work may be difficult and involve long hours, many staff see the work as "worth it" if they see how their efforts positively impact other campers and staff.

\section{Camp Embeddedness and Value Alignment as Drivers of Retention}

Camp Embeddedness also appeared to be a powerful motivating factor for returning staff that can trump the challenges of camp life. In this study, previous positive experiences at camp, an appreciation for the natural environment and the outdoors, and meaningful relationships appeared to bring staff back. Again, evidence supporting the power of Camp Embeddedness appeared in both the quantitative and qualitative data. The fun camp environment and the lasting relationships created at camp have been noted as important outcomes of staff employment in other studies of camp staff, and this study appeared to demonstrate the effects of these outcomes on retention (see DeGraff \& Glover, 2003; Duerden et al., 2014; Henderson et al., 2007; Wahl-Alexander et al., 2017; Wilson \& Sibthorp, 2018).

Previous experiences at camp, whether as a camper or camp staff, and the relationships made at camp mattered to returning camp staff. The view that camp is a "second home" or an escape from "the real world" highlighted the special place that camp holds for many staff. The friendships, camp traditions, and sense of community that staff feel contributed strong feelings of job embeddedness. Returning staff in this study were not yet ready to give up the part of their lives that involved the camp experience. 
One's perceived Value Fit with camp work also drives retention. In this study, value alignment emerged as its own factor driving retention, separate from embeddedness. The high correlation between Camp Embeddedness and Value Fit helps support retention theory on job embeddedness within management literature (Hom et al., 2017; Lee, Burch, \& Mitchell, 2014). For returning camp staff, identifying with the mission, worldview, and programming of the camp mattered, though these aspects did not emerge as the primary motivators of retention in this study. However, if personal values do not align with the values of the organization, turnover is much more likely (Lee et al., 2014).

\section{Remaining Factors Driving Retention}

Beyond Job Impact, Camp Embeddedness, and Value Fit, four other factors appeared to drive the retention of camp employees. These include Staff Development, Management, Job Interest, and Compensation. Returning staff appreciate opportunities to grow, learn new things and take on more responsibility. They are more likely to return if they feel like the job aligns with their experience, skills, and abilities. They appreciate work that is interesting and allows for autonomy. All these factors are consistent with the management literature as key drivers of engagement and motivating factors of retention (Hancock et al., 2013; Hom et al., 2017; Selden \& Sowa, 2015).

It is interesting, though perhaps unsurprising, that respondents rated Compensation the lowest among all factors related to retention. Camp pay is low when you consider the long hours associated with camp work-from consoling homesick campers late at night to rarely having a day off. Those staff that choose to return want to be compensated fairly but money is not the main reason they return. Making a difference and returning to a positive camp community matter more than money.

\section{The Flip Side of Retention}

While compensation may not be a driver of retention among camp employees, money may eventually motivate camp staff to seek out other employment. The nature of seasonal camp work leaves it vulnerable to losing employees to life scripts like graduating college, seeking work more closely related to one's education, or prioritizing other life events like starting a family (cf. DeGraff \& Glover, 2003; Whitacre \& Farmer, 2016). Pay factors into each of these life scripts. 
Motivations and Barriers for Seasonal Camp Employment

Camps may lose other staff simply because the job is not a good fit for the employee, even when the job initially appeared to be a good fit. In the qualitative data, many returning staff indicated camp work to be fun. However, other staff may find the long hours and emotional strain of working at camp not worth the toll the job takes. When discussing poor job fit as a likely driver of turnover, many respondents hypothesized that staff may choose not to return to camp work due to feelings of burnout. Feelings of burnout are common in highly-intensive seasonal work like summer camp (Fairlie, 2011; Wahl-Alexander et al., 2017). Staff unable to find the space for self-care or individuals that do not thrive in high-intensity environments are less likely to stay.

Camps must also fight the inevitable when retaining staff. At some point, many staff simply "age out" of camp employment. They graduate college and start careers with year-round employment. Other staff may simply choose to pursue other developmental opportunities to grow personally or build skills and experience. Findings from the qualitative responses on reasons for leaving camp employment and the opportunity costs of camp employment highlight how camp employees have many other competing interests. For example, a potential staff member may have a fear of missing out with friends over a long summer or may want to pursue study abroad, internships, travel, and other intriguing experiences. Losing camp staff to life scripts and other appealing alternatives are largely out of the employer's control (Allen \& Vardaman, 2017; Whitacre \& Farmer, 2016)

\section{Implications for Practice}

This study contributes to the literature on staff working in youth development fields by identifying and describing the key motivations and barriers for staff retention and turnover among seasonal summer camp staff. Findings from this study may help camp leadership better understand what drives staff to return and develop strategies to hold on to their best employees for more than one summer.

Most camp leadership would suspect that their staff return because they feel like they are making a difference and that they love the camp community, being outdoors, and living in the "camp bubble" (Johnson, Goldman, Garey, Britner, \& Weaver, 2011). For these leaders, this study confirms that they need to find the right individuals that will thrive in that environment. The fact that over $60 \%$ of the respondents in this study had participated in CIT or LIT programs prior to working as full-time seasonal camp staff demonstrated that previous positive camp 
Motivations and Barriers for Seasonal Camp Employment

experiences produce future dedicated staff. The question then is how do camps improve experiences for staff in the limited time they will work at camp?

Camps may want to consider how they can support staff within an environment that is both developmentally rich and transient. At some point, seasonal camp staff will move on to careers and other opportunities. The challenge is to make the most of that extra summer or two of camp employment.

Perhaps the answers may lie in being intentional about establishing 2- to 3-year developmental models for camp staff that allow returning staff to take on new responsibilities, mentor others, and amplify their impact on the campers they serve. This strategy could be a simple programmed progression of moving from junior to senior counselor or it could also be more intentional, where camps help returning employees craft their own development. This process of "job sculpting" may involve camp leadership working directly with returning camp staff to align desirable skill development with workplace needs and opportunities. For example, a returning staff member studying child development in college may be encouraged to design staff training materials and activities for new employees or a management major may be encouraged to facilitate peer feedback sessions for other staff.

Intentional staff development models would embrace the challenges of having young staff likely to stay for a limited time. By encouraging job sculpting, camps could benefit from the energy and excitement of their staff members who are eager to share their newfound knowledge and ideas assembled from their education and experiences. More entrenched employees with years of experience may not be as eager to try new things and take risks.

Other strategies exist that camps may want to consider so that they can keep their best seasonal staff for one or more additional summers. One such consideration may mean employing key staff for shorter or more flexible contracts so that these staff can also pursue other opportunities in the summer like internships, travel, study abroad, other employment, or summer classes.

The need for creative thinking becomes apparent when retaining quality seasonal staff is at issue. The costs of recruiting, selecting, and training new staff is just too high if camps are replacing $40 \%$ or more of their employees each year. Developing new models of camp staff 
development is worth the time and resources if it means keeping the right people dedicated to making a difference.

\section{Limitations and Future Research}

While this study has its strengths-employing a mixed methods approach to a large national sample of camp employees-it does have its limitations. First, only returning staff were queried, so participants provided the most useful data on motivations for returning to camp and the opportunity costs of summer camp employment. While these participants offered some insight on what may drive camp turnover, they were able to overcome these barriers to retention as they were returning to camp employment. Future research may want to employ longitudinal models to gather information from both returning and non-returning staff to better understand motivations for retention and turnover. Second, the instrument used in this study-though based on existing retention literature-has only been tested and refined within this study sample. As validity testing is an ongoing process, the concepts, constructs, and scales used in this study would benefit from additional assessment. Finally, the need for longitudinal research should not be understated. As many camp staff are drawn to camp work by the desire to make a difference, camp professionals need to understand where former camp employees go after leaving their jobs in camp. By understanding the career trajectories of former camp staff, the camping industry may be able to evaluate the role of camp employment in the development of future leaders.

\section{Conclusion}

This study sought to gain more insight on the key motivations that drive retention and turnover of seasonal summer camp staff. Among returning camp staff, perceived job impact and camp embeddedness were the primary drivers of retention and these factors were more important than compensation. At the same time, this study demonstrated the power of life scriptsgraduating college, starting careers, aging out of camp employment-on turnover. For camps this means maximizing the limited time they do have with employees, leveraging employees' desire to make a difference and their enthusiasm for camp life. This may mean implementing more intentional staff development models to keep the best employees engaged and interested in returning for one or two more summers before they move on to other life opportunities. Losing seasonal camp employees from year to year is an unavoidable challenge for camp leaders. Yet camps have the power to invest in their staff members, providing opportunities for growth and increased autonomy, to improve both performance and retention. 
Journal of Youth Development | http://jyd.pitt.edu/ | Vol. 15 Issue 1 DOI 10.5195/jyd.2020.822

Motivations and Barriers for Seasonal Camp Employment

\section{References}

Allen, D. G., Bryant, P. C., \& Vardaman, J. M. (2010). Retaining talent: Replacing misconceptions with evidence-based strategies. Academy of Management Perspectives, 24(2), 48-64. https://doi.org/10.5465/AMP.2010.51827775

Allen, D. G., \& Vardaman, J. M. (2017). Recruitment and retention across cultures. Annual Review of Organizational Behavior, 4, 153-181. https://doi.org/10.1146/annurev-orgpsych-032516-113100

American Camp Association. (2016). Camps sites, facilities, and program report. Bloomington, Indiana.

Brown, S., Gray, D., McHardy, J., \& Taylor, K. (2015). Employee trust and workplace performance. Journal of Economic Behavior and Organization. https://doi.org/10.1016/j.jebo.2015.05.001

DeGraff, D., \& Glover, J. (2003). Long-term impacts of working at an organized camp for seasonal staff. Journal of Park \& Recreation Administration, 21(1), 1-20.

Duerden, M. D., Witt, P., Garst, B. A., Bialeschki, D., Schwarzlose, T., \& Norton, K. (2014). The impact of camp employment on the workforce development of emerging adults. Journal of Park \& Recreation Administration, 32(1), 26-44.

Fairlie, P. (2011). Meaningful work, employee engagement, and other key employee outcomes: Implications for human resource development. Advances in Developing Human Resources, 13(4), 508-525. https://doi.org/10.1177/1523422311431679

Govaerts, N., Kyndt, E., Dochy, F., \& Baert, H. (2011). Influence of learning and working climate on the retention of talented employees. Journal of Workplace Learning, 23(1), 35-55. https://doi.org/10.1108/13665621111097245

Hancock, J. I., Allen, D. G., Bosco, F. A., McDaniel, K. R., \& Pierce, C. A. (2013). Meta-analytic review of employee turnover as a predictor of firm performance. Journal of Management, 39(3), 573-603. https://doi.org/10.1177/0149206311424943

Hausknecht, J. P., Rodda, J., \& Howard, M. J. (2009). Targeted employee retention: Performance-based and job-related differences in reported reasons for staying. Human Resource Management, 48(2), 269-288. https://doi.org/10.1002/hrm.20279

Henderson, K. A., Bialeschki, M. D., \& James, P. A. (2007). Overview of camp research. Child and Adolescent Psychiatric Clinics of North America, 16(4), 755-767.

https://doi.org/10.1016/j.chc.2007.05.010

Hom, P. W., Lee, T. W., Shaw, J. D., \& Hausknecht, J. P. (2017). One hundred years of employee turnover theory and research. Journal of Applied Psychology, 102(3), 530-545. https://doi.org/10.1037/apl0000103

Johnson, S. K., Goldman, J. A., Garey, A. I., Britner, P. A., \& Weaver, S. E. (2011). Emerging adults' identity exploration: Illustrations from inside the "camp bubble." Journal of Adolescent Research, 26(2), 258-295. https://doi.org/10.1177/0743558410376832 
Journal of Youth Development | http://jyd.pitt.edu/ | Vol. 15 Issue 1 DOI 10.5195/jyd.2020.822

Motivations and Barriers for Seasonal Camp Employment

Kahn, W. A. (1990). Psychological conditions of personal engagement and disengagement at work. The Academy of Management Journal, 33(4), 692-724. http://www.jstor.org/stable/256287

Kusluvan, S., Kusluvan, Z., Ilhan, I., \& Buyruk, L. (2010). The human dimension: A review of human resources management issues in the tourism and hospitality industry. Cornell Hospitality Quarterly, 51(2), 171-214. https://doi.org/10.1177/1938965510362871

Lee, T. W., Burch, T., \& Mitchell, T. R. (2014). The story of why we stay: A review of job embeddedness. Annual Review of Organizational Psychology and Organizational Behavior, 1, 199-216. https://doi.org/10.1146/annurev-orgpsych-031413-091244

Lee, T. W., Hom, P., Eberly, M., \& Li, J. (2018). Managing employee retention and turnover with $21^{\text {st }}$ century ideas. Organizational Dynamics, 47(2), 88-98.

\section{https://doi.org/10.1016/j.orgdyn.2017.08.004}

Maslow, A. H. (1970). Motivation and personality ( $2^{\text {nd }}$ ed.). New York, NY: Harper \& Row.

McCole, D., Jacobs, J., Lindley, B., \& McAvoy, L. (2012). The relationship between seasonal employee retention and sense of community: The case of summer camp employment. Journal of Park \& Recreation Administration, 30(2), 85-101.

Miles, M. B., Huberman, A. M., \& Saldana, J. (2014). Qualitative data analysis: A methods sourcebook (3 ${ }^{\text {rd }}$ ed.). Thousand Oaks, CA: Sage Publications.

Mitchell, T. R., Holtom, B. C., \& Lee, T. W. (2001). How to keep your best employees: Developing an effective retention policy. Academy of Management Executive, 15(4), 96-108.

\section{https://doi.org/10.5465/AME.2001.5897929}

Nagaoka, J., Farrington, C. A., Ehrlich, S. B., \& Heath, R. D., Johnson, D. W., Dickson, S., ... Hayes, K. (2015). Foundations for young adu/t success: A development framework. Chicago, IL: University of Chicago, Consortium on School Research. https://consortium.uchicago.edu/publications/foundations-young-adult-success-developmentalframework

Posthuma, R. A., \& Campion, M. A. (2013). A high performance work practices taxonomy: Integrating the literature and directing future research. Journal of Management, 39(5), 1184-1220. https://doi.org/10.1177/0149206313478184

Powell, G. M., Bixler, R. D., \& Switzer, D. M. (2003). Perceptions of learning among new and returning seasonal camp staff. Journal of Park \& Recreation Administration, 21(1), 61-74.

Selden, S. C., \& Sowa, J. E. (2015). Voluntary turnover in nonprofit human service organizations: The impact of high performance work practices. Human Service Organizations Management, Leadership \& Governance, 39(3), 182-207. https://doi.org/10.1080/23303131.2015.1031416

Wahl-Alexander, Z., Richards, K. A., \& Washburn, N. (2017). Changes in perceived burnout among camp staff across the summer camp season. Journal of Park and Recreation Administration, 35(2), 7485. https://doi.org/10.18666/jpra-2017-v35-i2-7417 
Journal of Youth Development | http://jyd.pitt.edu/ | Vol. 15 Issue 1 DOI 10.5195/jyd.2020.822

Motivations and Barriers for Seasonal Camp Employment

Whitacre, J., \& Farmer, J. (2016). How come the best job I ever had was when I worked at a summer camp?: Understanding retention among camp counselors. Journal of Youth Development, $8(2)$, 29-40. https://doi.org/10.5195/jyd.2013.94

Wilson, C., \& Sibthorp, J. (2018). Examining the role of summer camps in developing academic and workplace readiness. Journal of Youth Development, 13(1-2), 83-104.

https://doi.org/10.5195/JYD.2018.563

Yeager, D. S., Henderson, M., D’Mello, S., Paunesku, D., Walton, G., Spitzer, B., \& Duckworth, A. (2017). Boring but important: A self-transcendent purpose for learning fosters academic self-regulation. Journal of Personality and Social Psychology, 1074), 559-580. https://doi.org/10.1037/a0037637

Yeager, D. S., Romero, C., Paunesku, D., Hulleman, C. S., Schneider, B., Hinojosa, C., . . Dweck, C. S. (2016). Using design thinking to improve psychological interventions: The case of the growth mindset during the transition to high school. Journal of Educational Psychology, 108(3), 374-391. https://doi.org/10.1037/edu0000098 